\title{
CALGARY BLUEBIRD TRAIL -1978
}

AROLD W. PINEL, 1017 - 19 Avenue N.W., Calgary, Alberta and JOHN RIDDELL, 3033 - 1 street S.W., Calgary, Alberta.

During March of 1978, the 400 esting boxes were again cleaned ut, sprayed with a $10 \%$ creolin olution, and repaired or replaced, as equired, in preparation for the upoming nesting season. Each box as checked and the contents reorded three times between third eek in May to third week in July.

Of the 400 houses, 39 were vanalized before nesting began, and 11 ere unoccupied on all visits, eaving 350 boxes used by birds. Exluding the 39 houses vandalized efore nesting commenced, $96.9 \%$ of he available nesting boxes were ocupied. There were 392 bird nests, 1 ed Squirrel nest, and 4 Deer Mouse ests in the 350 occupied boxes.

Table 1 analyzes the nesting sucess and losses for 1978. The verage clutch size for Mountain luebirds was 5.26, and for Tree wallows 5.46. In 26 nest boxes, there were two or more broods by the same species - 20 were House Sparrows, and 6 were Mountain Bluebirds. Different species nested in the same box 16 times, as follows: sparrow then swallow, 7; sparrow then bluebird, 1; bluebird then swallow, 8.

The total losses for all species from egg-laying to young leaving the nest were $460(22.5 \%)$ of which 287 $(14 \%)$ were House Sparrow losses due to destruction by the authors. These figures show a drastic reduction in losses as compared to 1977, where losses from the egg-laying stage to young leaving the nest totalled $930(46.7 \%)$. Two major factors contributing to the high productivity of 1978 as compared to 1977 are less vandalism and less interspecific competition, as illustrated by the following points: (1) The number of boxes vandalized before nesting

able 1. SUMMARY OF NESTING SUCCESS BY SPECIES, CALGARY LUEBIRD TRAIL - 1978. (Numbers in parentheses are losses from the revious stage).

$\begin{array}{lrrrrr}\text { Decies } & \text { Nests } & \begin{array}{r}\text { Eggs } \\ \text { laid }\end{array} & \begin{array}{r}\text { Eggs } \\ \text { hatched }\end{array} & \begin{array}{r}\text { Young } \\ \text { fledged }\end{array} & \begin{array}{r}\text { fledged } \\ \text { young }\end{array} \\ \text { ountain Bluebird } & 84 & 442 & 414(28) & 410(4) & 92.8 \% \\ \text { ee Swallow } & 241 & 1317 & 1189(128) & 1176(13) & 89.3 \% \\ \text { ouse Sparrow } & 65 & 287 & 54(233)^{*} & 0(54)^{*} & - \\ \text { ouse Wren } & 2 & 0 & 0(0) & 0(0) & - \\ \text { DTALS } & 392 & 2046 & 1657(389) & 1586(71) & 77.5 \%\end{array}$

Pestroyed by authors. 


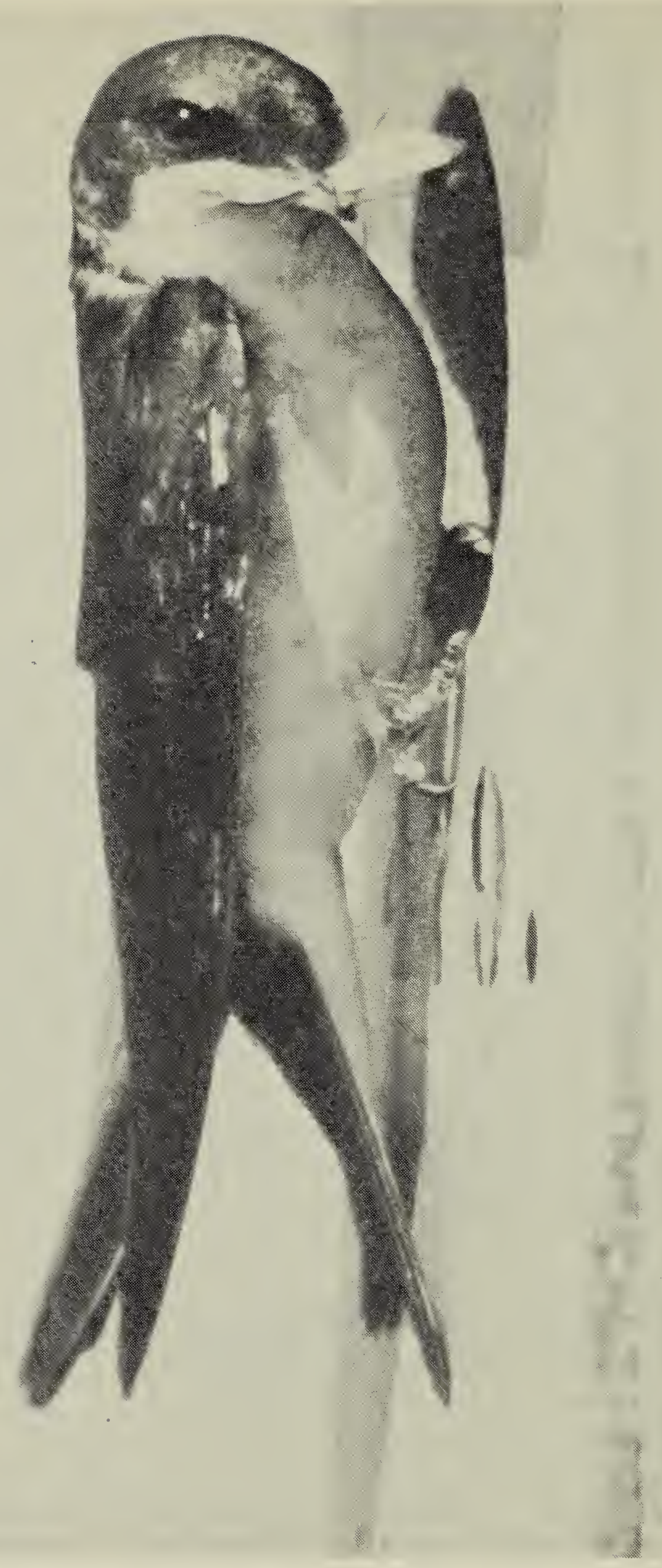

Tree Swallow at nesting box.

John Lane

began was reduced from 43 to 39 ; (2) The number of boxes vandalized after nesting began decreased from 15 to 0 ; (3) The number of House Sparrow nests decreased by 51 $(44 \%)$ in 1978; (4) The 65 House
Sparrow nests were concentrated in 45 boxes; and (5) The number 0 boxes used by more than one species during the nesting season decreased from 60 to 16 . 